\title{
Application of Hollow-Core Photonic Crystal Fibers in Gas Raman Lasers Operating at $1.7 \mu \mathrm{m}$
}

\author{
Jun $\mathrm{Li}^{1}$, Hao Li ${ }^{2}$ and Zefeng Wang ${ }^{2,3, *}$ \\ 1 Environmental Economy and Information Department, Changsha Environmental Protection Vocational \\ College, Changsha 410004, China; lijun@cshbxy.com \\ 2 College of Advanced Interdisciplinary Studies, National University of Defense Technology, \\ Changsha 410073, China; lihao18c@nudt.edu.cn \\ 3 State Key Laboratory of Pulsed Power Laser Technology, Changsha 410073, China \\ * Correspondence: zefengwang@nudt.edu.cn or zefengwang@nudt.edu.com
}

Citation: Li, J.; Li, H.; Wang, Z. Application of Hollow-Core Photonic Crystal Fibers in Gas Raman Lasers Operating at $1.7 \mu \mathrm{m}$. Crystals 2021, 11, 121. https://doi.org/10.3390/ cryst11020121

Academic Editors: David Novoa and Nicolas Y. Joly

Received: 30 December 2020

Accepted: 25 January 2021

Published: 27 January 2021

Publisher's Note: MDPI stays neutral with regard to jurisdictional claims in published maps and institutional affiliations.

Copyright: (c) 2021 by the authors. Licensee MDPI, Basel, Switzerland. This article is an open access article distributed under the terms and conditions of the Creative Commons Attribution (CC BY) license (https:// creativecommons.org/licenses/by/ $4.0 /)$

\begin{abstract}
A $1.7 \mu \mathrm{m}$ pulsed laser plays an important role in bioimaging, gas detection, and so on Fiber gas Raman lasers (FGRLs) based on hollow-core photonic crystal fibers (HC-PCFs) provide a novel and effective method for fiber lasers operating at $1.7 \mu \mathrm{m}$. Compared with traditional methods, FGRLs have more advantages in generating high-power $1.7 \mu \mathrm{m}$ pulsed lasers. This paper reviews the studies of $1.7 \mu \mathrm{m}$ FGRLs, briefly describes the principle and characteristics of HC-PCFs and gas-stimulated Raman scattering (SRS), and systematical characterizes $1.7 \mu \mathrm{m}$ FGRLs in aspects of output spectral coverage, power-limiting factors, and a theoretical model. When the fiber length and pump power are constant, a relatively high gas pressure and appropriate pump peak power are the key to achieving high-power $1.7 \mu \mathrm{m}$ Raman output. Furthermore, the development direction of $1.7 \mu \mathrm{m}$ FGRLs is also explored.
\end{abstract}

Keywords: stimulated Raman scattering; hollow-core photonic crystal fibers; fiber lasers; gas lasers

\section{Introduction}

In recent years, lasers operating in the $1.7 \mu \mathrm{m}$ band $(1650-1750 \mathrm{~nm})$ have received much attention due to the growing number of promising applications, such as bioimaging, gas detection, medical treatment, and mid-infrared laser generation. Compared with other types of lasers, $1.7 \mu \mathrm{m}$ fiber lasers have been more intensively studied due to good stability, compactness, and beam quality. However, reported works mainly involve $1.7 \mu \mathrm{m}$ continuous-wave (CW) fiber lasers [1,2], and the pulsed fiber lasers operating in this wavelength region have not been researched fully, though they have unique advantages in some applications. For example, in bioimaging applications such as multiphoton microscopy [3,4], optical coherence tomography [5], and spectroscopic photoacoustic (PA) imaging [6,7], $1.7 \mu \mathrm{m}$ pulsed lasers can be used to realize three-dimensional (3D) volumetric imaging by time-resolved ultrasonic detection [7]. Similarly, in methane detection, the 3D distribution of the $\mathrm{CH}_{4}$ concentration in space can be measured by using the time-of-flight ranging method to analyze the temporal characteristics of pulsed lasers when the pulsed lasers are in the $1.7 \mu \mathrm{m}$ band used as the detection signal [8]. In fact, whether in bioimaging or gas detection, high-power $1.7 \mu \mathrm{m}$ pulsed lasers are conducive to achieving higher sensitivity and deeper penetration/detection [7,9]. Thus, it is important and necessary to increase the output power of $1.7 \mu \mathrm{m}$ pulsed fiber lasers.

The traditional methods of realizing $1.7 \mu \mathrm{m}$ pulsed fiber lasers can be mainly classified into two categories. One is based on population inversion to generate $1.7 \mu \mathrm{m}$ pulsed lasers by using rare-earth-doped fibers, such as thulium-doped fibers $[6,7,10,11]$, thuliumholmium-codoped fibers [12,13], and bismuth-doped fibers [14-16]. The other is based on nonlinear effects in solid-core fibers to realize a frequency conversion, such as soliton self-frequency shift [17-20], four-wave mixing [21-23], self-phase modulation [7,24,25], and 
stimulated Raman scattering (SRS) [26]. Recently, fiber gas Raman lasers (FGRLs) based on hollow-core photonic crystal fibers (HC-PCFs) have opened a new opportunity for $1.7 \mu \mathrm{m}$ pulsed fiber lasers [27-30]. The principle of FGRLs is to realize a frequency conversion by gas SRS in HC-PCFs. The output average powers and corresponding pulse widths of reported $1.7 \mu \mathrm{m}$ pulsed fiber lasers are plotted in Figure 1.

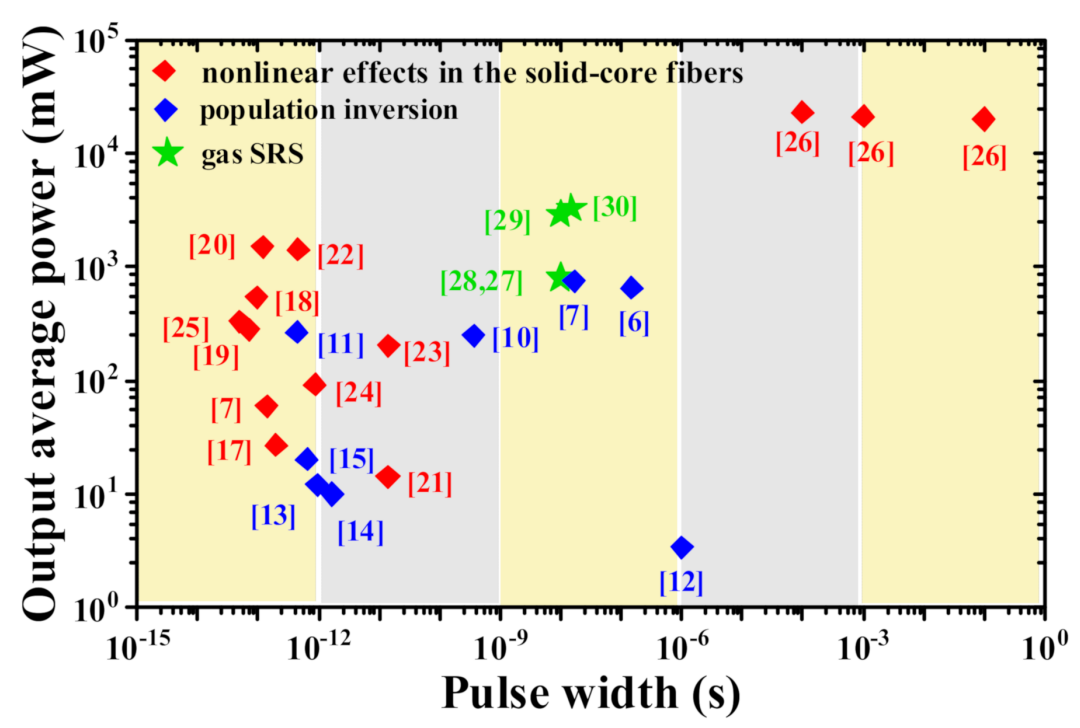

Figure 1. The output average powers and corresponding pulse widths of reported $1.7 \mu \mathrm{m}$ pulsed fiber lasers.

It can be seen that the pulse widths of $1.7 \mu \mathrm{m}$ pulsed lasers based on solid-core fibers are mostly in femtosecond and picosecond regions and their output average powers are mostly less than $1 \mathrm{~W}$. Only a pulsed Raman fiber laser can achieve an output power of up to $23 \mathrm{~W}$ [26], but its pulse width is at the millisecond level. Thus, it is very challenging to obtain high-power $1.7 \mu \mathrm{m}$ pulsed lasers with a short pulse width based on solid-core fibers. The $1.7 \mu \mathrm{m}$ FGRLs fill this gap and achieve nanosecond pulsed lasers with an output average power of over $3 \mathrm{~W}$ [30]. In fact, $1.7 \mu \mathrm{m}$ nanosecond short pulsed lasers have more advantages in bioimaging. To realize volumetric imaging with higher resolution, the pulse duration should be around $10 \mathrm{~ns}$ or even shorter [7]. Furthermore, $1.7 \mu \mathrm{m}$ FGRLs with continuous wavelength tunability and narrow linewidth also have more advantages in gas detection. Continuous wavelength tunability is conducive to the detection of different kinds of gas molecules, and narrow-linewidth pulsed lasers can not only accurately distinguish the absorption peaks but also have a longer coherent distance that is helpful in long-distance detection [9]. Therefore, compared with traditional $1.7 \mu \mathrm{m}$ pulsed fiber lasers, $1.7 \mu \mathrm{m}$ FGRLs have unique advantages and strong competitiveness due to the characteristics of high power, high efficiency, continuous wavelength tunability, and a narrow linewidth.

In this paper, we review the studies of $1.7 \mu \mathrm{m}$ FGRLs based on HC-PCFs. Section 2 briefly introduces the classification, light guide mechanism, and development of HCPCFs. In Section 3, a comparison of gas SRS in free space and in HC-PCFs is made and the characteristics of candidate Raman gas media for $1.7 \mu \mathrm{m}$ FGRLs are discussed. Section 4 describes the typical experimental structure of $1.7 \mu \mathrm{m}$ FGRLs and characterizes $1.7 \mu \mathrm{m}$ FGRLs in aspects of output spectral coverage, power-limiting factors, and a theoretical model. When the fiber length and pump power are constant, a relatively high gas pressure and appropriate pump peak power are the key to achieving high output Raman power in $1.7 \mu \mathrm{m}$ FGRLs. In Section 5, we discuss the future development of $1.7 \mu \mathrm{m}$ FGRLs based on HC-PCFs. 


\section{Hollow-Core Photonic Crystal Fibers}

HC-PCFs are the core components of FGRLs, which provide a platform for the interaction of laser and gas. The fiber core of an HC-PCF is an air hole, so the refractive index of the fiber core is less than that of the fiber cladding and the law of total reflection is not suitable for HC-PCFs. According to the light guide mechanism, there are two major classifications of HC-PCFs, namely photonic bandgap hollow-core fibers (PBG-HCFs) [31-35] and anti-resonance hollow-core fibers (AR-HCFs) (or inhibited-coupling fibers) [36-49].

\subsection{Photonic Bandgap Hollow-Core Fibers}

In 1999, Russell et al. demonstrated the first PBG-HCFs [31], the schematic cross section of which is shown in Figure 2a. It can be seen that the fiber core is a larger air hole and periodic small air holes are distributed in the cladding of the PBG-HCFs. These periodic air holes in the cladding form a two-dimensional photonic bandgap, so light cannot pass through the cladding and be confined in the fiber core when the wavelength of light is located in the photonic bandgap. Since then, HC-PCFs have been developed toward lower loss and greater bandwidths. In 2004, the University of Bath demonstrated lowloss PBG-HCFs of $1.72 \mathrm{~dB} / \mathrm{km}$ at $1565 \mathrm{~nm}$ [32], the schematic cross section of which is shown in Figure $2 \mathrm{~b}$. In 2005, they further reduced the fiber loss to $1.2 \mathrm{~dB} / \mathrm{km}$ at $1620 \mathrm{~nm}$ [33], which is currently the lowest loss of PBG-HCFs. Figure 2c shows the schematic cross section of PBG-HCFs with a broad transmission band and low loss demonstrated by the Beijing University of Technology in 2019 [34]. The minimum loss of $6.5 \mathrm{~dB} / \mathrm{km}$ at $1633 \mathrm{~nm}$ and a $3 \mathrm{~dB}$ bandwidth at $458 \mathrm{~nm}$ were achieved, which is the broadest bandwidth in PBG-HCFs. The main factors affecting the loss of PBG-HCFs are the scattering caused by the surface roughness of the fiber core boundary [33] and the coupling between the core and the surface modes [35]. Moreover, the coupling also causes multiple loss peaks in the transmission band, affecting the transmission bandwidth of the PBG-HCFs.
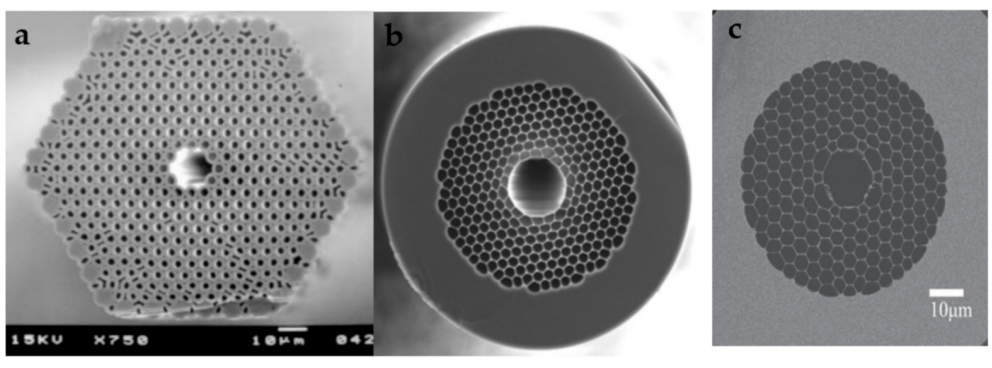

Figure 2. The schematic cross section of HC-PCFs. (a) The first PBG-HCF [31], (b) low-loss PBGHCF [32], and (c) broadband PBG-HCF [34].

\subsection{Anti-Resonance Hollow-Core Fibers}

The Kagome HCFs reported in 2002 are the first AR-HCFs [36], the schematic cross section of which is shown in Figure 3a. Compared with PBG-HCFs, the cladding structure pitch of Kagome HCFs is larger, which can widen the optical transmission band [37]. Furthermore, there is no complete photonic bandgap in the Kagome hollow fiber, and its light-guiding mechanism can be explained by inhibited coupling [38] or the anti-resonant reflection optical waveguide (ARROW) [39]. According to the inhibited-coupling mechanism, a core-guide mode can be strongly inhibited from channeling out through the cladding by a mismatch between the core and cladding modes [40]. According to ARROW, the microstructure in the cladding is similar to a Fabry-Perot cavity. The light that meets the cavity resonance conditions will leak out through the cladding, while the light that cannot resonate in the cavity is prevented from leaking from the cladding and confined to the fiber core [41]. Figure 3b shows the schematic cross section of hypocycloid Kagome HCFs, and the design of the fiber core boundary with negative curvature reduces the transmission loss of the fiber [42]. With further study of the light-guiding mechanism of AR-HCFs, 
it has been found that the transmission performance of AR-HCFs is mainly determined by the first ring microstructure of the fiber core boundary. Subsequently, AR-HCFs with simpler microstructures and better optical performance have emerged [43-49], and all of these AR-HCFs obey the ARROW guiding mechanism. Figure $2 \mathrm{c}$ presents the schematic cross section of the first tube-structure AR-HCFs reported in 2011, the cladding of which is composed of single-ring tubes [44]. The attenuation of the single-ring AR-HCFs in the mid-infrared band is much lower than that of the silica glass solid-core fiber. Figure $3 \mathrm{~d}$ shows the schematic cross section of ice-cream-type AR-HCFs [45], the transmission band of which is located in the mid-infrared band and the minimum loss of which is $34 \mathrm{~dB} / \mathrm{km}$ at $3050 \mathrm{~nm}$. With further study of AR-HCFs, it has been found that the touching points of adjacent capillaries in the cladding behave as independent waveguides supporting their own lossy modes, which would introduce additional transmission loss [50,51]. Thus, nodeless single-ring AR-HCFs were first demonstrated in 2013 [46]. In addition, it was demonstrated that the elimination of the tube's contact point helps to reduce the bending loss [47]. In 2019, nodeless nested AR-HCFs with the attenuation of $0.65 \mathrm{~dB} / \mathrm{km}$ in the C and $\mathrm{L}$ telecommunications bands were demonstrated, which means this was the first time that HC-PCFs realized a loss comparable to that of silica glass solid-core fibers [48]. The attenuation of nodeless nested AR-HCFs was further recued to $0.28 \mathrm{~dB} / \mathrm{km}$ in 2020 [49].

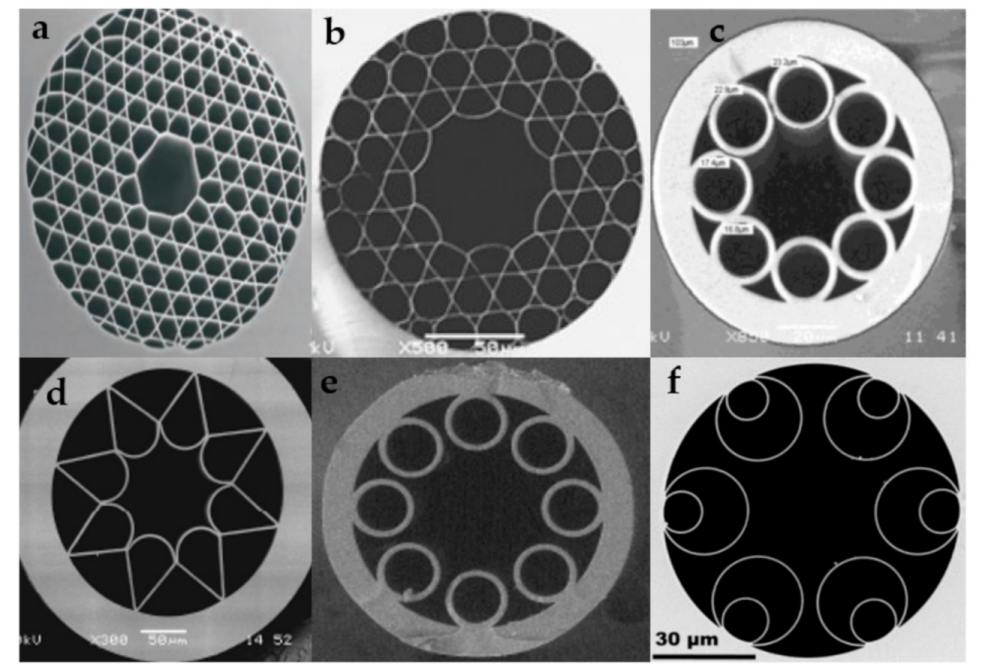

Figure 3. The schematic cross section of HC-PCFs. (a) The first AR-HCF [36], (b) hypocycloid Kagome AR-HCFs [42], (c) single-ring AR-HCFs [44], (d) ice-cream-type AR-HCF [45], (e) nodeless single-ring AR-HCFs [46], and (f) nodeless nested AR-HCFs [48].

Compared with PBG-HCFs, the mode field of AR-HCFs overlaps the silica glass of the fiber core boundary less [52]. Thus, the surface scattering loss of AR-HCFs is lower than that of PBG-HCFs, which means that AR-HCFs have advantages of realizing lower loss and reducing the nonlinearities caused by silica glass. Furthermore, although both AR-HCFs and PBG-HCFs are multimode, the attenuation of high-order modes in AR-HCFs is higher than that of PBG-HCFs, which means that with AR-HCFs it is easier to obtain a fundamental mode guidance at a short fiber length [53].

\section{Gas Stimulated Raman Scattering}

\subsection{Traditional Gas Raman Lasers Versus Fiber Gas Raman Lasers}

Since gas SRS was first reported in 1963 [54], gas SRS has been considered as a significant method to realize a laser of a new wavelength by frequency conversion. Gas SRS can cover the ultraviolet-to-infrared band [55,56], which is an effective extension of the laser output band. Figure $4 \mathrm{a}$ is a simplified schematic diagram of the interaction between lasers and gas in traditional Raman gas lasers. Owing to the diffraction effect of laser transmission in free space and some other factors, the gas SRS in free space has a short interaction length 
and low intensity, leading to an extremely high Raman threshold. Normally, traditional gas Raman lasers require pump pulsed lasers with megawatt peak power to reach the Raman threshold. Moreover, there would be many Stokes waves generated, so it is difficult to realize efficient conversion of a single Stokes wavelength in traditional gas Raman lasers. These problems limit the applications of traditional gas Raman lasers. However, for FGRLs, gas SRS occurs in HC-PCFs, and a simplified schematic diagram of the interaction between lasers and gas in FGRLs is shown in Figure 4b. HC-PCFs can confine lasers to the small core for long-distance transmission, so an extremely low Raman threshold can be achieved. Furthermore, the output Stokes waves can be controlled by designing the transmission band of HC-PCFs. Thus, HC-PCFs provide an ideal environment for efficient gas SRS, meeting the requirements of strong interaction intensity, a long interaction length, and a controllable Raman gain spectrum at the same time.

(a)

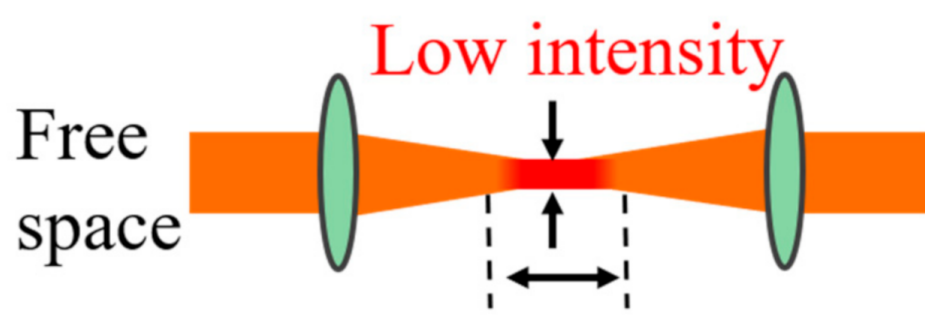

\section{Short interaction length}

(b)

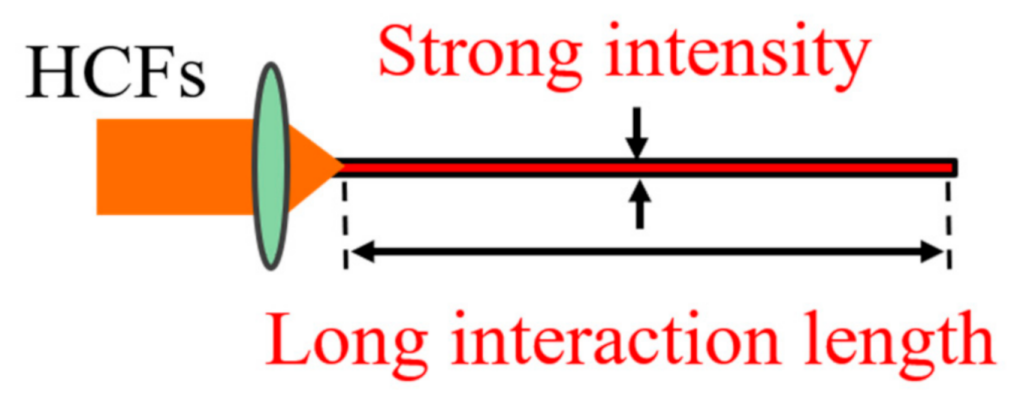

Figure 4. The simplified schematic diagram of the interaction between lasers and gas in (a) traditional gas Raman lasers and (b) fiber gas Raman lasers.

\subsection{Candidate Gas Media for $1.7 \mu \mathrm{m}$ Raman Wavelength}

For gas SRS, the Raman frequency shift is due to the energy-level transitions of gas media. Thus, different output Raman wavelengths can be flexibly realized by changing the gas media or using different energy-level transitions of one gas medium. Because hydrogen $\left(\mathrm{H}_{2}\right)$ and deuterium $\left(\mathrm{D}_{2}\right)$ are the main candidate gas media for $1.7 \mu \mathrm{m}$ FGRLs, Figure $5 \mathrm{a}, \mathrm{b}$ present the schematic diagrams of the energy-level transitions of $\mathrm{H}_{2}$ [57] and $\mathrm{D}_{2}$ SRS [58], respectively. It can be seen that $\mathrm{H}_{2}$ molecules' vibrational SRS has a Raman frequency shift coefficient of $\sim 4155 \mathrm{~cm}^{-1}$ and the rotational SRS of different energy levels has Raman frequency shift coefficients of $\sim 587, \sim 354$, and $\sim 814 \mathrm{~cm}^{-1}$. $\mathrm{D}_{2}$ molecules' vibrational SRS has a Raman frequency shift coefficient of $\sim 2988 \mathrm{~cm}^{-1}$, and the rotational SRS of different energy levels has Raman frequency shift coefficients of $\sim 179, \sim 297$, and $\sim 415 \mathrm{~cm}^{-1}$. 


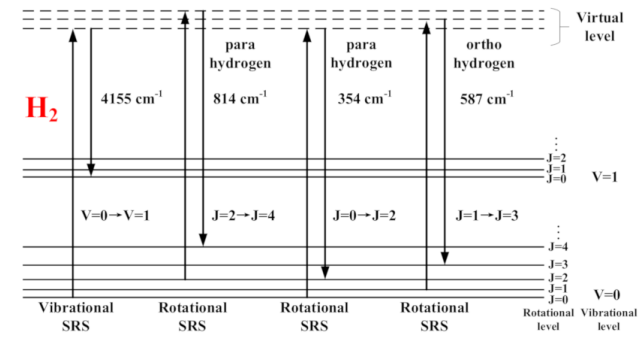

(a)

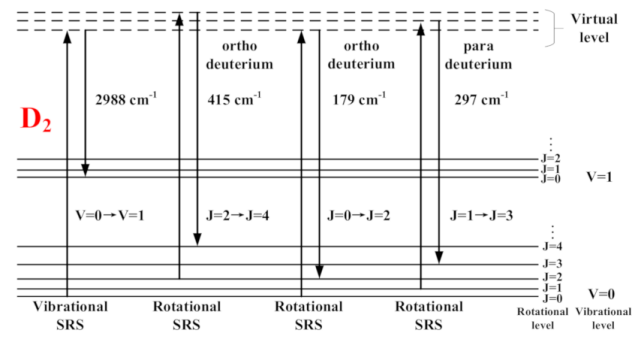

(b)

Figure 5. The schematic diagram of the energy-level transitions of (a) $\mathrm{H}_{2}$ [57] and (b) $\mathrm{D}_{2}$ [58] SRS.

The relationship between the pump wavelength, Raman frequency shift coefficient, and Raman wavelength is given by

$$
\Delta \omega=\frac{1}{\lambda_{p}}-\frac{1}{\lambda_{s}}
$$

where $\Delta \omega$ is the Raman frequency shift coefficient and $\lambda_{P}$ and $\lambda_{S}$ are the pump wavelength and Raman wavelength, respectively. When the pump wavelength is set in the 1 or $1.5 \mu \mathrm{m}$ band, $\mathrm{H}_{2}$ or $\mathrm{D}_{2}$ SRS can realize different output Raman wavelengths, as shown in Table 1. It can be seen that when the pump wavelength is set in the $1.5 \mu \mathrm{m}$ band, the output Raman wavelength at the $1.7 \mu \mathrm{m}$ band can be realized by $\mathrm{H}_{2}$ or $\mathrm{D}_{2}$ rotational SRS.

Table 1. Different pump wavelengths, Raman frequency shift, and corresponding output Raman wavelengths.

\begin{tabular}{cccc}
\hline Gain Gases & $\begin{array}{c}\text { Raman Frequency } \\
\text { Shift }\end{array}$ & $\begin{array}{c}\text { Raman Wavelength } \\
\text { Pumped at 1064 nm }\end{array}$ & $\begin{array}{c}\text { Raman Wavelength } \\
\text { Pumped at 1550 nm }\end{array}$ \\
\hline & $4155 \mathrm{~cm}^{-1}$ & $1907 \mathrm{~nm}$ & $4354 \mathrm{~nm}$ \\
& $814 \mathrm{~cm}^{-1}$ & $1165 \mathrm{~nm}$ & $1773 \mathrm{~nm}$ \\
$\mathrm{H}_{2}$ & $587 \mathrm{~cm}^{-1}$ & $1135 \mathrm{~nm}$ & $1705 \mathrm{~nm}$ \\
& $354 \mathrm{~cm}^{-1}$ & $1106 \mathrm{~nm}$ & $1640 \mathrm{~nm}$ \\
\hline & $2987 \mathrm{~cm}^{-1}$ & $1560 \mathrm{~nm}$ & $2886 \mathrm{~nm}$ \\
& $415 \mathrm{~cm}^{-1}$ & $1113 \mathrm{~nm}$ & $1656 \mathrm{~nm}$ \\
$\mathrm{D}_{2}$ & $297 \mathrm{~cm}^{-1}$ & $1098 \mathrm{~nm}$ & $1625 \mathrm{~nm}$ \\
& $179 \mathrm{~cm}^{-1}$ & $1084 \mathrm{~nm}$ & $1594 \mathrm{~nm}$
\end{tabular}

\section{Fiber Gas Raman Lasers Operating at $1.7 \mu \mathrm{m}$}

\subsection{Typical Experimental Setup}

Figure 6a presents the typical experimental setup of $1.7 \mu \mathrm{m}$ FGRLs, comprising mainly a pump source, $\mathrm{HC}-\mathrm{PCF}$, a gas cell, and a set of lenses. The pump laser is a $1.5 \mu \mathrm{m}$ pulsed erbium-doped fiber amplifier (EDFA), the pigtail fiber (Corning, SMF-28e) of which is fusion-spliced with the HC-PCFs (NKT Photonics, HC-1550-02) due to a similar mode field area and numerical aperture, and the theoretical minimum loss can be as low as $1.3 \mathrm{~dB}$ [59]. The output end of the HC-PCFs is sealed in a gas cell with a glass window, and the HC-PCFs can be filled with a gas medium through the gas cell. The output lasers being transmitted through the glass window are collimated and are filtered by a set of lenses. 

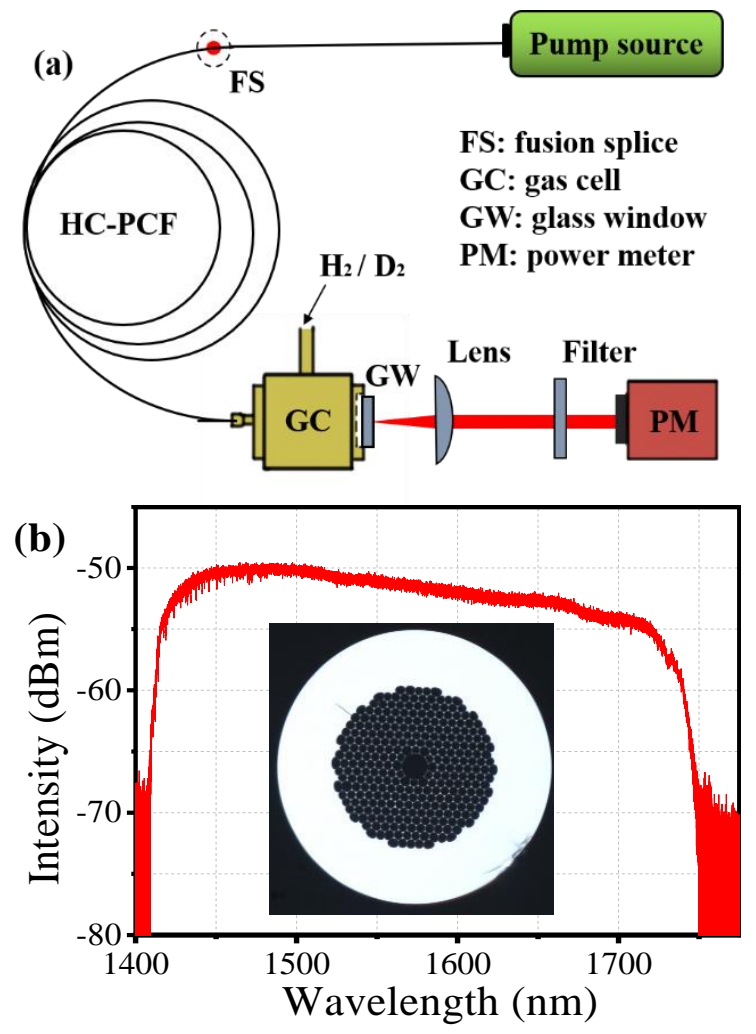

Figure 6. (a) The schematic diagram of a typical experimental setup of $1.7 \mu \mathrm{m}$ FGRLs and (b) the transmission spectrum of the used HC-PCFs. Insert: optical micrograph of a cross section of the used HC-PCFs [57].

Figure $6 \mathrm{~b}$ presents the transmission spectrum and optical micrograph of a cross section of HC-PCFs [57]. The low-loss transmission band of HC-PCFs is from 1415 to $1740 \mathrm{~nm}$, covering both the $1.5 \mu \mathrm{m}$ pump wavelengths and the $1.7 \mu \mathrm{m}$ output Raman wavelengths. Furthermore, it can be seen from the insert that the used HC-PCFs are PBG-HCFs with a multilayer microstructure in the cladding. Compared with the AR-HCFs with a single-ring microstructure in the cladding, fusion splicing has less impact on the optical performance of the used HC-PCFs. Thus, mature commercial HC-PCFs (NKT Photonics, HC-1550-02) are very suitable for $1.7 \mu \mathrm{m}$ FGRLs.

\subsection{Spectral Coverage}

A pulsed fiber amplifier with a wavelength tuning range of 1535-1565 nm was used to pump 20-m-long HC-PCFs filled with $\mathrm{D}_{2}$ or $\mathrm{H}_{2}$, and the output spectra are shown in Figure 7a [27] and Figure 7b [28], respectively. It can be seen that one pump line in the $1.5 \mathrm{um}$ band is converted into one Raman line in the $1.7 \mu \mathrm{m}$ band $\left(415\right.$ and $587 \mathrm{~cm}^{-1}$ Raman frequency shift coefficients of $\mathrm{D}_{2}$ and $\mathrm{H}_{2}$, respectively), which greatly improves the power conversion efficiency. This is not difficult to explain. Take $\mathrm{D}_{2}$ SRS as an example; if the pump wavelength is $1550 \mathrm{~nm}$, because the $2886 \mathrm{~nm}$ Raman line generated by vibrational SRS (with a Raman frequency shift of $2987 \mathrm{~cm}^{-1}$ ) is located outside the low-loss transmission band, it is strongly suppressed. Moreover, because the Raman gain of the $1656 \mathrm{~nm}$ rotational Raman line (with a Raman frequency shift of $415 \mathrm{~cm}^{-1}$ ) is higher than that of 1625 and $1594 \mathrm{~nm}$ rotational Raman lines (with Raman frequency shifts of 297 and $179 \mathrm{~cm}^{-1}$, respectively), the $1550 \mathrm{~nm}$ pump line will first be converted into a $1656 \mathrm{~nm}$ Raman line, and the residual pump power is too low to generate 1625 and $1594 \mathrm{~nm}$ Raman lines. The explanation of the output spectrum of $\mathrm{H}_{2}$ SRS is also similar. Therefore, the output Raman wavelengths are determined by the gas media, pump wavelength, and fiber attenuation. 

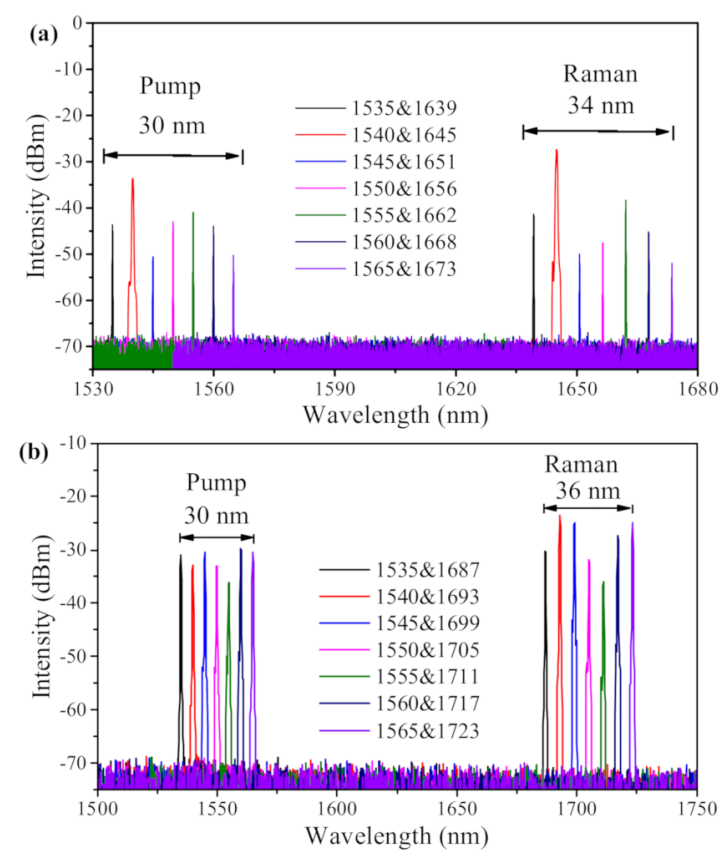

Figure 7. The output spectra of $1.7 \mu \mathrm{m}$ FGRLs based on (a) $\mathrm{D}_{2}$-filled [27] and (b) $\mathrm{H}_{2}$-filled HCPCFs [28] when the pump wavelength is from 1535 to $1565 \mathrm{~nm}$ and the fiber length is $20 \mathrm{~m}$.

\subsection{Power-Limiting Factors}

Compared to the solid-core fiber, only less than $1 \%$ of the mode field energy overlaps the silica glass of the fiber core boundary when the lasers are transmitted in HC-PCFs. So HC-PCFs have a higher damage threshold, which means that HC-PCFs are more capable of transmitting comparatively higher power and energy. In this section, the influence of the pump wavelength, gas pressure, repetition frequency of the pump pulse, and fiber length on the output Raman power is fully discussed based on the reported experimental results of the $1.7 \mu \mathrm{m}$ fiber deuterium gas Raman laser [27,29], and the key factors for achieving high-power $1.7 \mu \mathrm{m}$ FGRLs are analyzed.

Figure 8a shows the output Raman power as a function of coupled average pump power at different pump wavelengths when the fiber length is $20 \mathrm{~m}$ [27]. The maximum Raman power decreases toward the long wavelength. It can be attributed to the amplification performance of the pump source. The output power of the pump source is slightly reduced as the wavelength increases. In fact, when the fiber attenuation in the pump band and output Raman band is basically unchanged, the wavelength change has little effect on the output Raman power. Figure $8 \mathrm{~b}$ shows the output Raman power as a function of coupled average pump power at different gas pressures when the fiber length is $20 \mathrm{~m} \mathrm{[27].} \mathrm{Since} \mathrm{the}$ molecular density of the gain gas in the HC-PCFs can be adjusted by the barometer of the gas cell, this provides new freedom in the optimization of the $1.7 \mu \mathrm{m}$ FGRL performance for high-power laser emission. When the gas pressure is too low, the Raman threshold is relatively higher due to the small Raman gain [60], thereby affecting the output Raman power. While the Raman gain is saturated at a high gas pressure level, the contribution of increasing gas pressure to the Raman gain becomes extremely small. Therefore, it can be seen from Figure $7 \mathrm{~b}$ that when the gas pressure is higher than 15 bar, the Raman power does not increase obviously.

Figure 9 presents the experimental results of using a higher-power pump source [29], and cascaded Raman conversion is more likely to occur under high pump power. Figure 9a presents the output Raman power as a function of the coupled average pump power at different repetition frequencies of the pump pulse when the fiber length is $20 \mathrm{~m}$ and the gas pressure is 16 bar. It can be seen that the repetition frequency has a great influence on the output Raman power, and there is an optimal repetition frequency to achieve the maximum output Raman power. This is because when the fiber length 
and the gas pressure are constant, the Raman threshold of the pump peak power is also constant. Thus, it is necessary to adjust the repetition frequency to obtain a suitable peak power so that the peak power is much higher than the first-order Raman threshold but does not exceed the second-order Raman threshold. When the peak power is much higher than the first-order Raman threshold, more pump pulse energy can undergo Raman conversion. When the peak power does not exceed the second-order Raman threshold, the first-order to second-order cascaded Raman conversion will not occur, which means that the first-order Raman power will not fall at the high pump power level. Figure $8 \mathrm{~b}$ presents the output Raman power as a function of the coupled average pump power at different fiber lengths when the repetition is $1.5 \mathrm{MHz}$ and the gas pressure is 16 bar. It can be seen that the Raman threshold increases with a decrease in the fiber length, which means that less pump pulse energy is converted into Raman pulse energy, so the maximum output Raman power also decreases. Therefore, when the fiber length is reduced, a higher peak power of the pump pulse is required to improve the power conversion efficiency.
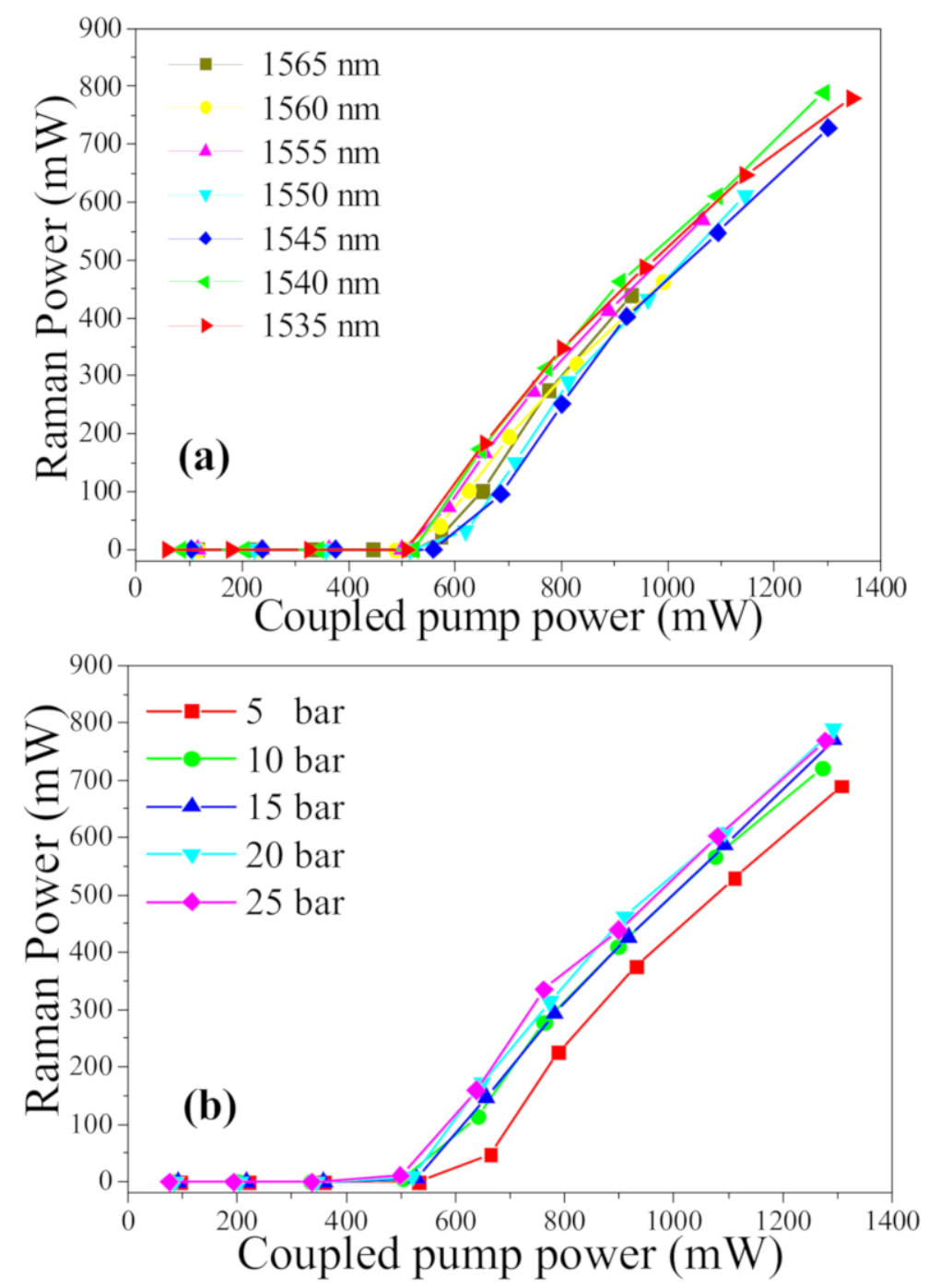

Figure 8. The output Raman power as a function of coupled pump power at different (a) pump wavelengths and (b) gas pressures when the fiber length is $20 \mathrm{~m}$ [27]. 

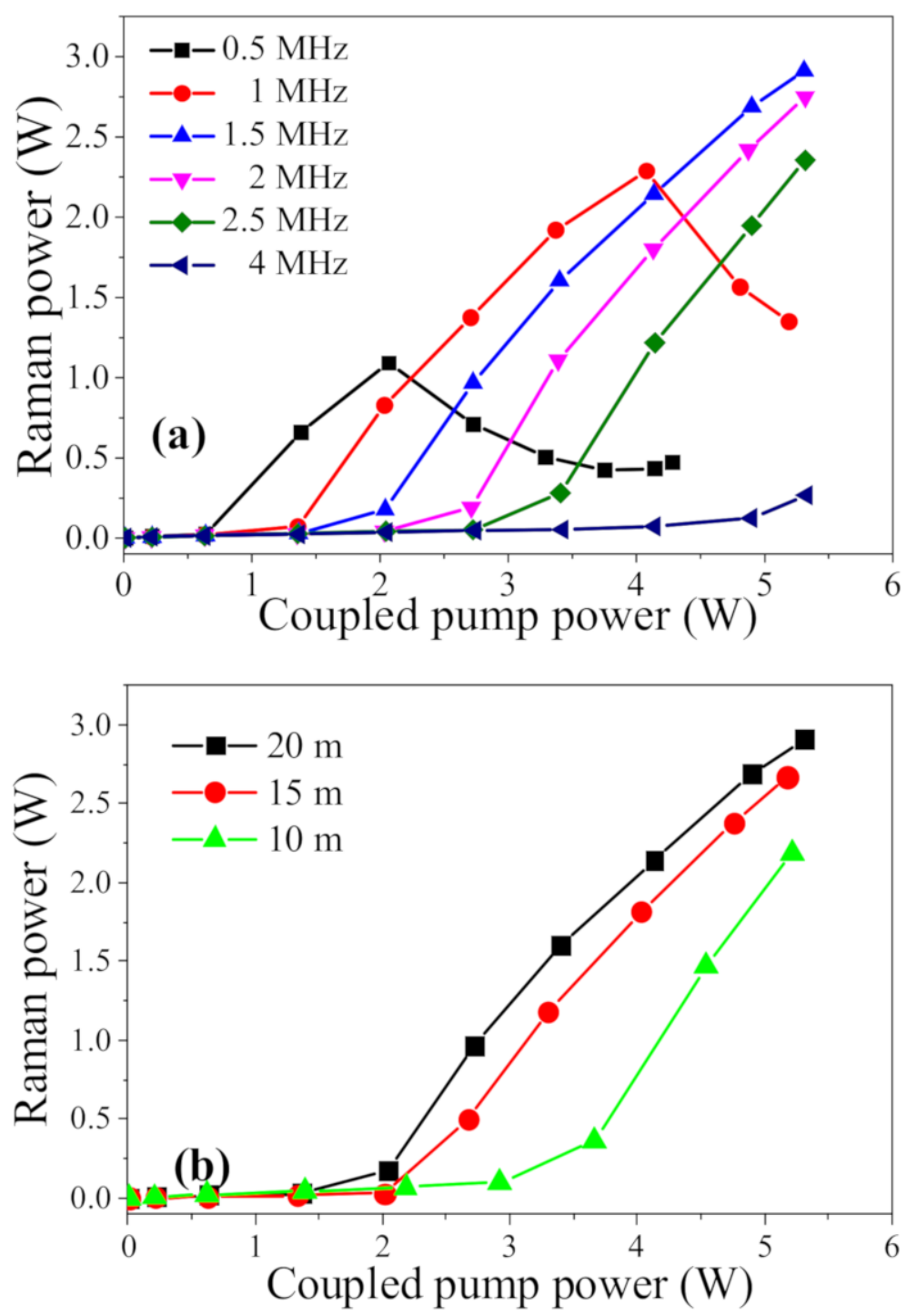

Figure 9. The output Raman power as a function of coupled pump power (a) at different repetition frequencies of the pump pulse when the fiber length is $20 \mathrm{~m}$ and the gas pressure is 16 bar and (b) at different fiber lengths when the repetition frequency is $1.5 \mathrm{MHz}$ and the gas pressure is 16 bar [29].

\subsection{Theoretical Model}

Because there are many adjustable experimental parameters in $1.7 \mu \mathrm{m}$ FGRLs, it is necessary to establish a corresponding theoretical model to guide the actual experiment to obtain a higher output Raman power. In fact, the $1.7 \mu \mathrm{m}$ fiber hydrogen Raman laser has the following characteristics: First, there is only a pure rotational SRS process in the HC-PCFs; second, there is only one rotational Raman line generated by the rotational SRS; and third, there is only one second-order Raman line generated by the cascade Raman conversion. Therefore, the theoretical model is greatly simplified, and a steady-state coupled wave equation considering cascaded Raman conversion and pulse shape is established [57].

$$
\left\{\begin{array}{l}
\frac{d I_{S 2}}{d z}=g_{S 2} I_{S 2} I_{S 1}-\alpha_{S 2} I_{S 2} \\
\frac{d I_{S 1}}{d z}=g_{S 1} I_{S 1} I_{p}-\alpha_{S 1} I_{S 1}-\frac{v_{S 1}}{v_{S 2}} g_{S 2} I_{S 2} I_{S 1} \\
\frac{d I_{P}}{d z}=-\frac{v_{P}}{v_{S 1}} g_{S 1} I_{S 1} I_{P}-\alpha_{P} I_{P}
\end{array}\right.
$$

where $I_{\mathrm{x}}$ is the intensity, $\alpha_{\mathrm{x}}$ is the fiber loss, $v_{\mathrm{x}}$ is the frequency, and $g_{\mathrm{x}}$ is the steady-state Raman gain coefficient ( $x$ means S1 for the first-order Stokes wave, S2 for the second-order 
Stokes wave, and $\mathrm{P}$ for the pump wave); $z$ is the position of the fiber along the propagation. The boundary conditions of Equation (2) are set as follows [57]:

$$
\left\{\begin{array}{l}
I_{P}(z=0)=I_{o} e^{-\frac{t^{2}}{2 \sigma^{2}}} \\
I_{S 1}(z=0)=\frac{h v_{S 1} \pi \Delta v_{R}}{A_{e f f}}
\end{array}\right.
$$

where $I_{0}$ is the initial pump intensity, $h$ is the Planck constant, $\Delta v_{\mathrm{R}}$ is the Raman linewidth, $A_{\text {eff }}$ is the mode field area of the HC-PCFs, $\sigma$ is the variance of the Gaussian distribution, and $t$ is the pump pulse width.

The above theoretical model is used for simulation, and simulation parameters such as fiber length, pump power, and Raman gain are set according to actual experimental conditions. The simulation and measured results of pulse shapes are shown in Figure 10 [57]. Figure 10a,b present the pulse shapes in the condition of no cascaded Raman conversion, and the simulation results reproduce the measured results very well. The center part of the pump pulse is converted into a Raman pulse, so there is a dip in the middle of the residual pump pulse. When the peak power is extremely high, the first-order Raman light is converted into second-order Raman light, so there is also a dip in the middle of the first-order Raman pulse, as shown in Figure 10c,d. The difference between the simulation and the measured results of the Raman pulse shape is caused by the gain accumulation [61], and the gain accumulation is not considered in the simulation as the pump pulse builds up.
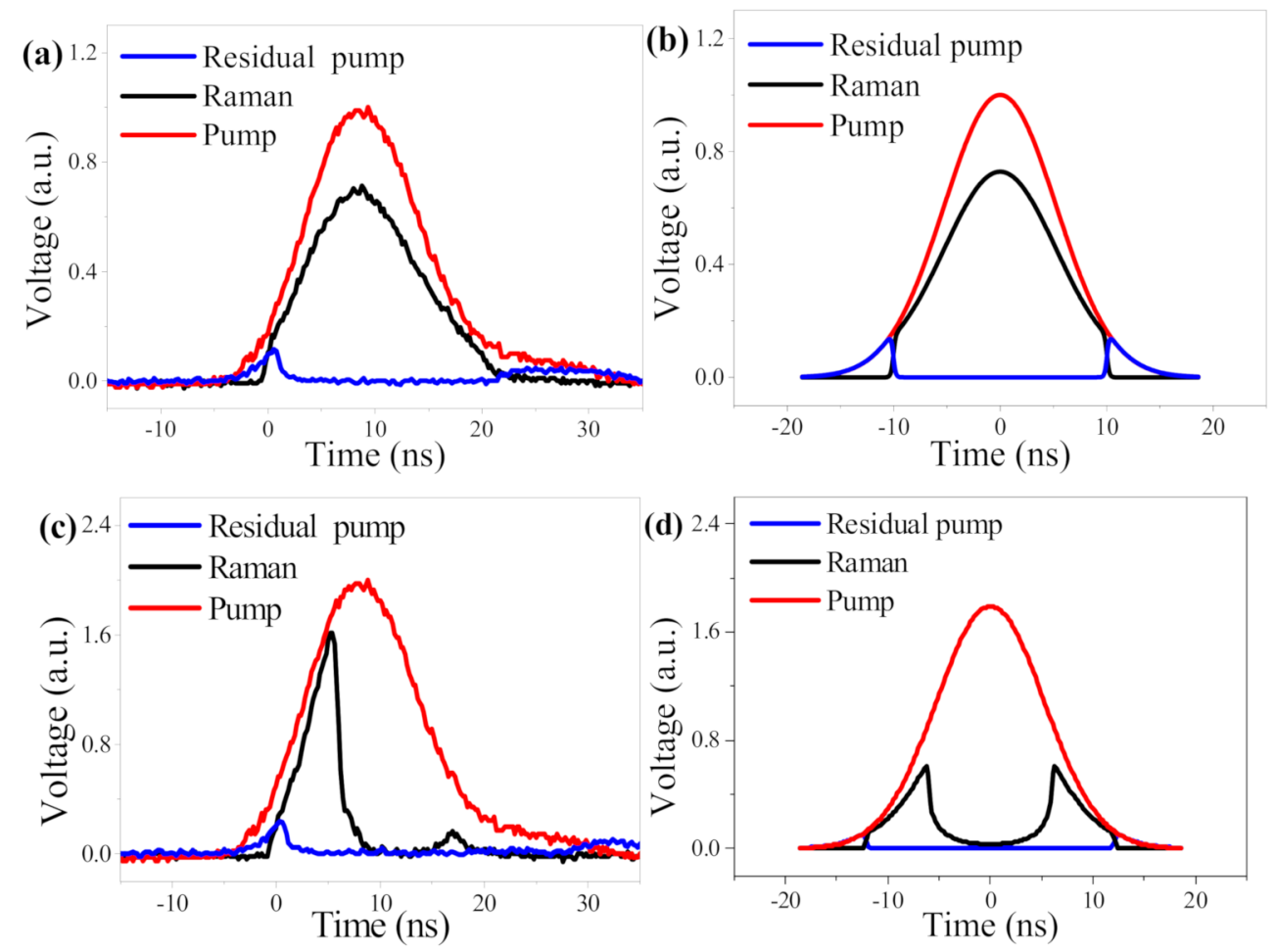

Figure 10. (a,c) Measured pulse shapes of pump light, first-order Raman light, and residual pump light; (b,d) corresponding simulation results [57].

Similarly, the simulation evolution curves of the output power with the repetition frequency of the pump pulse are calculated when the fiber length, gas pressure, and average pump power are constant [30], as shown in Figure 11a. The simulation and measured results are plotted using dotted lines and solid-core patterns, respectively. It can be seen that simulation results can find the optical repetition frequency relatively accurately. Furthermore, the simulation evolution curves of the output power with the 
fiber length are also calculated when the pump power and gas pressure are constant [57], as shown in Figure 11b. It can be seen that the measured results are basically consistent with the simulation results. Thus, the theoretical model is relatively reliable and can have an important guiding role in achieving high-power $1.7 \mu \mathrm{m}$ FGRLs.
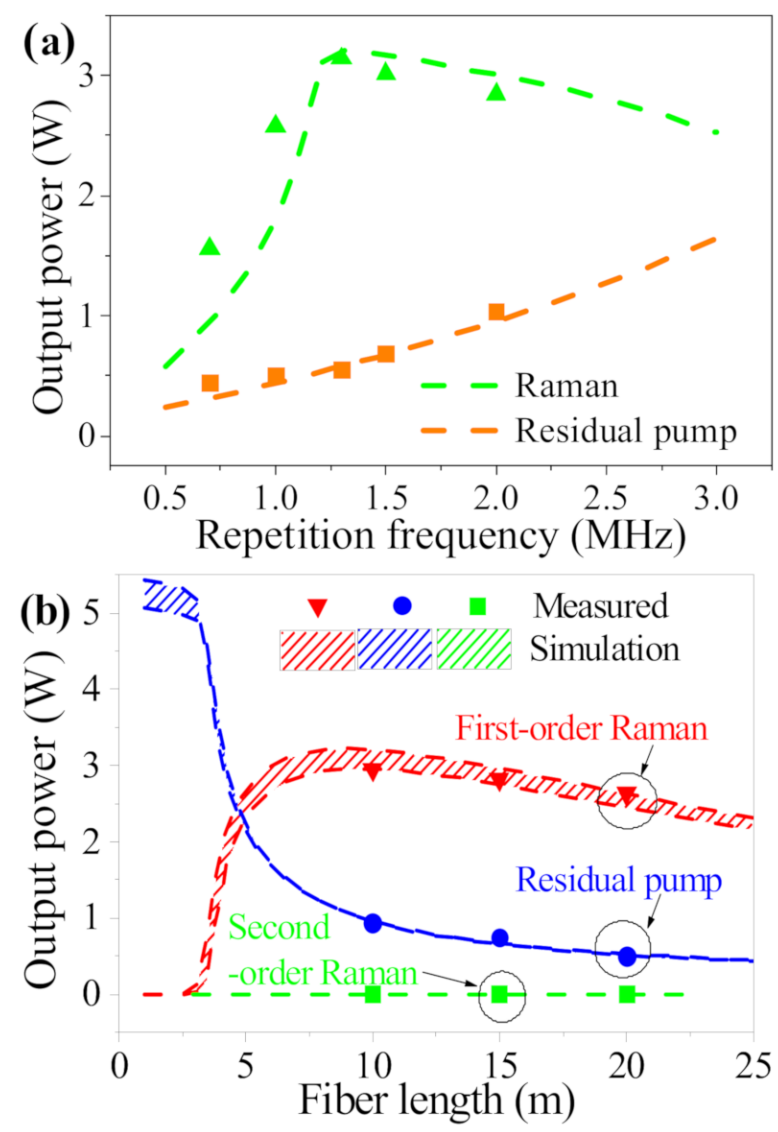

Figure 11. (a) The output power as a function of repetition frequency of the pump pulse when the fiber length, gas pressure, and average pump power are constant, and the dotted lines and solid-core patterns represent simulation and measured results, respectively [30]; (b) the output power as a function of fiber length when the pump power and gas pressure are constant [57].

\section{Summary and Outlook}

In summary, we reviewed the studies of $1.7 \mu \mathrm{m}$ FGRLs based on HC-PCFs. We briefly described the principle and characteristics of HC-PCFs and the gas SRS process and systematically characterized $1.7 \mu \mathrm{m}$ FGRLs in aspects of output spectral coverage, power-limiting factors, and a theoretical model. There are two important facts to improve the output Raman power for $1.7 \mu \mathrm{m}$ FGRLs when the fiber length and pump power are constant. One is to keep the gas pressure at a high level to ensure Raman gain saturation in the HC-PCFs. The other is to adjust the parameters of the pump pulse so the peak power is of an appropriate value, that is, the peak power is much larger than the first-order Raman threshold and slightly smaller than the second-order Raman threshold.

We believe that $1.7 \mu \mathrm{m}$ FGRLs will develop toward higher power and an all-fiber structure. There is no Raman power saturation in the current works, so if more pump power were coupled into the HC-PCFs, a higher output Raman power would be obtained. A useful way is to use a higher-power $1.5 \mu \mathrm{m}$ pump source and introduce transition fibers to reduce the fusion-splice loss between HC-PCFs and solid-core fibers [62]. To realize an all-fiber structure, it is necessary to solve the problem of HC-PCFs being fusion-spliced with the solid-core fibers in the gas-filled state, which may face the danger of gas leakage and combustion [63]. Furthermore, a $1.7 \mu \mathrm{m}$ all-fiber gas Raman laser with a Fabry-Perot 
cavity is also one of the development directions, and the introduction of the Fabry-Perot cavity can further reduce the Raman threshold [64]. However, because $\mathrm{H}_{2}$ molecules and $\mathrm{D}_{2}$ molecules are extremely small, they can penetrate the silica glass and overflow from the HC-PCFs, which could affect the long-term reliability of the $1.7 \mu \mathrm{m}$ FGRL. This problem also needs to be further studied and solved.

Author Contributions: Conceptualization, Z.W.; software, H.L.; investigation, J.L. and H.L.; writingoriginal draft preparation, J.L.; and writing-review and editing, H.L. and Z.W. All authors have read and agreed to the published version of the manuscript.

Funding: This research was funded by the Outstanding Youth Science Fund Project of the Hunan Province Natural Science Foundation (2019JJ20023), the National Natural Science Foundation of China (NSFC) $(11974427,12004431)$, and the Fund of State Key Laboratory of Pulsed Power Laser Technology (SKL 2020 ZR05).

Conflicts of Interest: The authors declare no conflict of interest.

\section{References}

1. Burns, M.D.; Shardlow, P.C.; Barua, P.; Jefferson-Brain, T.L.; Sahu, J.K.; Clarkson, W.A. 47 W continuous-wave 1726 nm thulium fiber laser core-pumped by an erbium fiber laser. Opt. Lett. 2019, 44, 5230-5233. [CrossRef] [PubMed]

2. Zhang, Y.; Song, J.; Ye, J.; Xu, J.; Yao, T.; Zhou, P. Tunable random Raman fiber laser at $1.7 \mu \mathrm{m}$ region with high spectral purity. Opt. Express 2019, 27, 28800-28807. [CrossRef]

3. Cheng, H.; Tong, S.; Deng, X.; Liu, H.; Du, Y.; He, C. Deep-brain 2-photon fluorescence microscopy in vivo excited at the $1700 \mathrm{~nm}$ window. Opt. Lett. 2019, 44, 4432-4435. [CrossRef] [PubMed]

4. Horton, N.G.; Xu, C. Dispersion compensation in three-photon fluorescence microscopy at $1700 \mathrm{~nm}$. Biomed. Opt. Express 2015, 6, 1392-1397. [CrossRef] [PubMed]

5. Kawagoe, H.; Ishida, S.; Aramaki, M.; Sakakibara, Y.; Omoda, E.; Kataura, H. Development of a high-power supercontinuum source at the $1.7 \mu \mathrm{m}$ wavelength region for highly penetrative ultrahigh-resolution optical coherence tomography. Biomed. Opt. Express 2014, 5, 932-943. [CrossRef]

6. Li, C.; Shi, J.; Gong, X.; Kong, C.; Luo, Z.; Song, L. $1.7 \mu \mathrm{m}$ wavelength tunable gain-switched fiber laser and its application to spectroscopic photoacoustic imaging. Opt. Lett. 2018, 43, 5849-5852. [CrossRef]

7. Li, C.; Shi, J.; Wang, X.; Wang, B.; Gong, X.; Song, L. High-energy all-fiber gain-switched thulium-doped fiber laser for volumetric photoacoustic imaging of lipids. Photonics Res. 2020, 8, 160-164. [CrossRef]

8. Li, B.; Zheng, C.; Liu, H.; He, Q.; Ye, W.; Zhang, Y.; Pan, J.; Wang, Y. Development and measurement of a near-infrared CH detection system using $1.654 \mu \mathrm{m}$ wavelength-modulated diode laser and open reflective gas sensing probe. Sens. Actuators $B$ Chem. 2016, 225, 188-198. [CrossRef]

9. Yin, T.; Qi, Z.; Chen, F.; Song, Y.; He, S. High peak-power and narrow-linewidth all-fiber Raman nanosecond laser in $1.65 \mu \mathrm{m}$ waveband. Opt. Express 2020, 28,7175-7181. [CrossRef]

10. Li, C.; Kong, C.; Wong, K.K.Y. High Energy Noise-Like Pulse Generation from a Mode-Locked Thulium-Doped Fiber Laser at 1.7 $\mu \mathrm{m}$. IEEE Photonics J. 2019, 11, 1-6. [CrossRef]

11. Li, C.; Wei, X.; Kong, C.; Tan, S.; Chen, N.; Kang, J. Fiber chirped pulse amplification of a short wavelength mode-locked thulium-doped fiber laser. APL Photonics 2017, 2, 121302. [CrossRef]

12. Du, T.; Ruan, Q.; Yang, R.; Li, W.; Wang, K.; Luo, Z. 1.7- $\mu \mathrm{m}$ Tm/Ho-Codoped All-Fiber Pulsed Laser Based on Intermode-Beating Modulation Technique. J. Lightwave Technol. 2018, 36, 4894-4899. [CrossRef]

13. Noronen, T.; Okhotnikov, O.; Gumenyuk, R. Electronically tunable thulium-holmium mode-locked fiber laser for the 1700-1800 nm wavelength band. Opt. Express 2016, 24, 14703-14708. [CrossRef]

14. Noronen, T.; Firstov, S.; Dianov, E.; Okhotnikov, O.G. $1700 \mathrm{~nm}$ dispersion managed mode-locked bismuth fiber laser. Sci. Rep. 2016, 6, 24876. [CrossRef] [PubMed]

15. Khegai, A.; Melkumov, M.; Riumkin, K.; Khopin, V.; Firstov, S.; Dianov, E. NALM-based bismuth-doped fiber laser at $1.7 \mu$ m. Opt. Lett. 2018, 43, 1127-1130. [CrossRef]

16. Thipparapu, N.K.; Wang, Y.; Wang, S.; Umnikov, A.A.; Barua, P.; Sahu, J.K. Bi-doped fiber amplifiers and lasers [Invited]. Opt. Mater. Express 2019, 9, 2446-2465. [CrossRef]

17. Fang, X.; Wang, Z.Q.; Zhan, L. Efficient generation of all-fiber femtosecond pulses at $1.7 \mu \mathrm{m}$ via soliton self-frequency shift. Opt. Eng. 2017, 56, 046107. [CrossRef]

18. Nguyen, T.N.; Kieu, K.; Churin, D.; Ota, T.; Miyawaki, M.; Peyghambarian, N. High Power Soliton Self-Frequency Shift with Improved Flatness Ranging From 1.6 to $1.78 \mu \mathrm{m}$. IEEE Photonics Technol. Lett. 2013, 25, 1893-1896. [CrossRef]

19. Wang, $\mathrm{K} . ; \mathrm{Xu}, \mathrm{C}$. Tunable high-energy soliton pulse generation from a large-mode-area fiber and its application to third harmonic generation microscopy. Appl. Phys. Lett. 2011, 99, 071112. [CrossRef]

20. Zach, A.; Mohseni, M.; Polzer, C.; Nicholson, J.W.; Hellerer, T. All-fiber widely tunable ultrafast laser source for multimodal imaging in nonlinear microscopy. Opt. Lett. 2019, 44, 5218-5221. [CrossRef] 
21. Becheker, R.; Tang, M.; Hanzard, P.H.; Tyazhev, A.; Mussot, A.; Kudlinski, A. High-energy dissipative soliton-driven fiber optical parametric oscillator emitting at $1.7 \mu \mathrm{m}$. Laser Phys. Lett. 2018, 15, 115103. [CrossRef]

22. Qin, Y.; Batjargal, O.; Cromey, B.; Kieu, K. All-fiber high-power $1700 \mathrm{~nm}$ femtosecond laser based on optical parametric chirped-pulse amplification. Opt. Express 2020, 28, 2317-2325. [CrossRef] [PubMed]

23. Tang, M.; Becheker, R.; Hanzard, P.H.; Tyazhev, A.; Oudar, J.L.; Mussot, A. Low Noise High-Energy Dissipative Soliton Erbium Fiber Laser for Fiber Optical Parametric Oscillator Pumping. Appl. Sci. 2018, 8, 2161. [CrossRef]

24. Zeng, J.; Akosman, A.E.; Sander, M.Y. Supercontinuum Generation from a Thulium Ultrafast Fiber Laser in a High NA Silica Fiber. IEEE Photonics Technol. Lett. 2019, 31, 1787-1790. [CrossRef]

25. Chung, H.Y.; Liu, W.; Cao, Q.; Kartner, F.X.; Chang, G. Er-fiber laser enabled, energy scalable femtosecond source tunable from 1.3 to $1.7 \mu \mathrm{m}$. Opt. Express 2017, 25, 15760-15771. [CrossRef] [PubMed]

26. Grimes, A.; Hariharan, A.; Sun, Y.; Ovtar, S.; Kristensen, P.; Westergaard, P.G.; Rako, S.; Baumgarten, C.; Stoneman, R.C.; Nicholson, J.W.; et al. Hundred-watt CW and Joule level pulsed output from Raman fiber laser in 1.7- $\mu$ m band. In Proceedings of the SPIE 11260, Fiber Lasers XVII: Technology and Systems, San Francisco, CA, USA, 21 February 2020.

27. Cui, Y.; Huang, W.; Li, Z.; Zhou, Z.; Wang, Z. High-efficiency laser wavelength conversion in deuterium-filled hollow-core photonic crystal fiber by rotational stimulated Raman scattering. Opt. Express 2019, 27, 30396-30404. [CrossRef]

28. Huang, W.; Li, Z.; Cui, Y.; Zhou, Z.; Wang, Z. Efficient, watt-level, tunable $1.7 \mu \mathrm{m}$ fiber Raman laser in $\mathrm{H}_{2}$-filled hollow-core fibers. Opt. Lett. 2020, 45, 475-478. [CrossRef]

29. Li, H.; Huang, W.; Cui, Y.; Zhou, Z.; Wang, Z. 3 W tunable $1.65 \mu \mathrm{m}$ fiber gas Raman laser in $\mathrm{D}_{2}$-filled hollow-core photonic crystal fibers. Opt. Laser Technol. 2020, 132, 106474. [CrossRef]

30. Li, H.; Pei, W.; Huang, W.; Cui, Y.; Wang, M.; Wang, Z. Highly efficient nanosecond $1.7 \mu \mathrm{m}$ fiber gas Raman laser by $\mathrm{H}_{2}$-filled hollow-core photonic crystal fibers. Crystals 2021, 11, 32. [CrossRef]

31. Cregan, R.F.; Mangan, B.J.; Knight, J.C.; Birks, T.A.; Russell, P.S.J.; Roberts, P.J.; Allan, D.C. Single-Mode Photonic Band Gap Guidance of Light in Air. Science 1999, 285, 1537-1539. [CrossRef]

32. Mangan, B.J.; Farr, L.; Langford, A.; Roberts, P.J.; Williams, D.P.; Couny, F.; Lawman, M.; Mason, M.; Coupland, S.; Flea, R. Low loss $(1.7 \mathrm{~dB} / \mathrm{km})$ hollow core photonic bandgap fiber. In Proceedings of the Optical Fiber Communication Conference, Los Angeles, CA, USA, 22 February 2004.

33. Roberts, P.J.; Couny, F.; Sabert, H.; Mangan, B.J.; Russell, P.S.J. Ultimate low loss of hollow-core photonic crystal fibres. Opt. Express 2005, 13, 236-244. [CrossRef] [PubMed]

34. Zhang, X.; Gao, S.; Wang, Y.; Ding, W.; Wang, X.; Wang, P. 7-cell hollow-core photonic bandgap fiber with broad spectral bandwidth and low loss. Opt. Express 2019, 27, 11608-11616. [CrossRef] [PubMed]

35. Smith, C.M.; Venkataraman, N.; Gallagher, M.T.; Muller, D.; West, J.A.; Borrelli, N.F.; Allan, D.C.; Koch, K.W. Low-loss hollow-core silica/air photonic bandgap fibre. Nature 2003, 424, 657-659. [CrossRef] [PubMed]

36. Benabid, F.; Knight, J.C.; Antonopoulos, G.; Russell, P.S.J. Stimulated Raman scattering in hydrogen-filled hollow-core photonic crystal fiber. Science 2002, 298, 399-402. [CrossRef]

37. Couny, F.; Benabid, F.; Light, P.S. Large-pitch kagome-structured hollow-core photonic crystal fiber. Opt. Lett. 2006, 31, 3574-3576. [CrossRef]

38. Couny, F.; Benabid, F.; Roberts, P.J.; Light, P.S.; Raymer, M.G. Generation and photonic guidance of multi-octave optical-frequency combs. Science 2007, 318, 1118-1121. [CrossRef]

39. Pearce, G.J.; Wiederhecker, G.S.; Poulton, C.G.; Burger, S. Models for guidance in kagome-structured hollow-core photonic crystal fibres. Opt. Express 2007, 15, 12680-12685. [CrossRef]

40. Debord, B.; Amsanpally, A.; Chafer, M.; Baz, A.; Maurel, M.; Blondy, J.M.; Hugonnot, E.; Scol, F.; Vincetti, L.; Gérôme, F.; et al. Ultralow transmission loss in inhibited-coupling guiding hollow fibers. Optica 2017, 4, 209-217. [CrossRef]

41. Litchinitser, N.M.; Abeeluck, A.K.; Headley, C. Antiresonant reflecting photonic crystal optical waveguides. Opt. Lett. 2002, 27, 1592-1594. [CrossRef]

42. Wang, Y.Y.; Wheeler, N.V.; Couny, F. Low loss broadband transmission in hypocycloid-core Kagome hollow-core photonic crystal fiber. Opt. Lett. 2011, 36, 669-671. [CrossRef]

43. Gérôme, F.; Jamier, R.; Auguste, J.L. Simplified hollow-core photonic crystal fiber. Opt. Lett. 2010, 35, 1157-1159. [CrossRef] [PubMed]

44. Pryamikov, A.D.; Biriukov, A.S.; Kosolapov, A.F.; Plotnichenko, V.G.; Semjonov, S.L.; Dianov, E.M. Demonstration of a waveguide regime for a silica hollow-core micro structured optical fiber with a negative curvature of the core boundary in the spectral region $>3.5 \mu \mathrm{m}$. Opt. Express 2011, 19, 1441-1448. [CrossRef] [PubMed]

45. Yu, F.; Wadsworth, W.J.; Knight, J.C. Low loss silica hollow core fibers for 3-4 $\mu \mathrm{m}$ spectral region. Opt. Express 2012, 20, 11153-11158. [CrossRef]

46. Kolyadin, A.N.; Kosolapov, A.F.; Pryamikov, A.D.; Biriukov, A.S.; Plotnichenko, V.G.; Dianov, E.M. Light transmission in negative curvature hollow core fiber in extremely high material loss region. Opt. Express 2013, 21, 9514-9519. [CrossRef] [PubMed]

47. Gao, S.F.; Wang, Y.Y.; Liu, X.L. Bending loss characterization in nodeless hollow-core anti-resonant fiber. Opt. Express 2016, 24, 14801-14811. [CrossRef] 
48. Bradley, T.D.; Jasion, G.T.; Hayes, J.R. Antiresonant Hollow Core Fibre with $0.65 \mathrm{~dB} / \mathrm{km}$ Attenuation across the C and L Telecommunication bands. In Proceedings of the 45th European Conference on Optical Communication, Dublin, Ireland, 26 September 2019.

49. Jasion, G.T.; Bradley, T.D.; Harrington, K.; Sakr, H.; Chen, Y.; Fokoua, E.N.; Davidson, I.A.; Taranta, A.; Hayes, J.R.; Richardson, D.J. Hollow Core NANF with $0.28 \mathrm{~dB} / \mathrm{km}$ Attenuation in the $\mathrm{C}$ and L Bands. In Proceedings of the 2020 Optical Fiber Communications Conference and Exhibition, San Diego, CA, USA, 8 March 2020.

50. Vincetti, L.; Setti, V. Extra loss due to Fano resonances in inhibited coupling fibers based on a lattice of tubes. Opt. Express 2012, 20, 14350-14361. [CrossRef]

51. Jaworski, P.; Yu, F.; Maier, R.R.J.; Wadsworth, W.J.; Knight, J.C.; Shephard, J.D.; Hand, D.P. Picosecond and nanosecond pulse delivery through a hollow-core Negative Curvature Fiber for micro-machining applications. Opt. Express 2013, 21, 22742-22753. [CrossRef]

52. Bufetov, I.A.; Kosolapov, A.F.; Pryamikov, A.D.; Gladyshev, A.V.; Kolyadin, A.N.; Krylov, A.A.; Yatsenko, Y.P.; Biriukov, A.S. Revolver Hollow Core Optical Fibers. Fibers 2018, 6, 39. [CrossRef]

53. Komanec, M.; Dousek, D.; Suslov, D.; Zvanove, S. Hollow-Core Optical Fibers. Radioengineering 2020, 29, 417-430. [CrossRef]

54. Minck, R.W.; Terhune, R.W.; Rado, W.G. Laser stimulated Raman effect and resonant four-photon interactions in gases $\mathrm{H}_{2}$, $\mathrm{D}_{2}$, and $\mathrm{CH}_{4}$. Appl. Phys. Lett. 1963, 3, 181-183. [CrossRef]

55. Brink, D.J.; Proch, D. Efficient tunable ultraviolet source based on stimulated Raman scattering of an excimer-pumped dye laser. Opt. Lett. 1982, 7, 494-496. [CrossRef] [PubMed]

56. Loree, T.R.; Cantrell, C.D.; Barker, D.L. Stimulated Raman emission at $9.2 \mu \mathrm{m}$ from hydrogen gas. Opt. Commun. 1976, 17, 160-162. [CrossRef]

57. Li, H.; Huang, W.; Cui, Y.; Zhou, Z.; Wang, Z. Pure rotational stimulated Raman scattering in $\mathrm{H}_{2}$-filled hollow-core photonic crystal fibers. Opt. Express 2020, 28, 23881-23897. [CrossRef]

58. Teal, G.K.; MacWood, G.E. The Raman Spectra of the Isotopic Molecules $\mathrm{H}_{2}, \mathrm{HD}$, and $\mathrm{D}_{2}$. J. Chem. Phys. 1935, 3, 760-764. [CrossRef]

59. Aghaie, K.Z.; Digonnet, M.J.F.; Fan, S. Optimization of the splice loss between photonic-bandgap fibers and conventional single-mode fibers. Opt. Lett. 2010, 35, 1938-1940. [CrossRef]

60. Bischel, W.K.; Dyer, M.J. Wavelength dependence of the absolute Raman gain coefficient for the Q(1) transition in $\mathrm{H}_{2}$. J. Opt. Soc. Am. B 1986, 3, 677-682. [CrossRef]

61. Benabid, F.; Antonopoulos, G.; Knight, J.C.; Russell, P.S.J. Stokes amplification regimes in quasi-cw pumped hydrogen-filled hollow-core photonic crystal fiber. Phys. Rev. Lett. 2005, 95, 213903. [CrossRef]

62. Gao, S.; Wang, Y.; Tian, C.; Wang, P. Splice Loss Optimization of a Photonic Bandgap Fiber via a High V-Number Fiber. IEEE Photonics Technol. Lett. 2014, 26, 2134-2137. [CrossRef]

63. Benabid, F.; Couny, F.; Knight, J.C.; Birks, T.A.; Russell, P.S. Compact, stable and efficient all-fibre gas cells using hollow-core photonic crystal fibres. Nature 2005, 434, 488-491. [CrossRef]

64. Couny, F.; Benabid, F.; Light, P.S. Subwatt threshold cw Raman fiber-gas laser based on $\mathrm{H}_{2}$-filled hollow-core photonic crystal fiber. Phys. Rev. Lett. 2007, 99, 143903. [CrossRef] 